\title{
Challenges for nursing human resources
}

\section{Silvia Helena De Bortoli Cassiani}

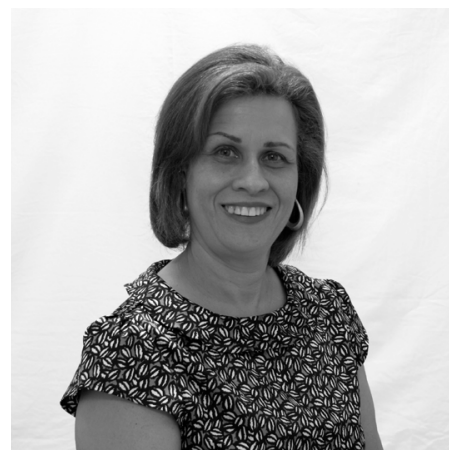

In 2013, the University of São Paulo at Ribeirão Preto College of Nursing (EERP-USP) and the Latin American Journal of Nursing (RLAE), its official scientific dissemination vehicle, celebrate 60 and 20 years of existence, respectively. In addition, EERP-USP will also celebrate its 25 years as a WHO Collaborating Centre.

Among international commemorations, the "International Nurses Day" should be highlighted, celebrated on May $12^{\text {th }}$. This year, the International Council of Nurses (ICN), a federation of 130 national associations that represent 13 million nurses, has selected the theme "Closing the gap: Millennium Development Goals $8,7,6,5,4,3,2,1^{\prime \prime}$.

RLAE has disseminated studies about the Millennium Development Goals (MDG) and, in 2007, a special issue was published, with an editorial and 24 papers, to disclose research results about the Goal "Eradicating extreme poverty and hunger"(1). Keeping up this journal's contributions to the discussions of the MDG, the theme ICN proposed is highlighted in this editorial.

One of the challenges to achieve mainly the MDG, considering health and nursing professionals, is to expand these professionals' access to information and scientific knowledge, which remains limited nowadays ${ }^{(2)}$.

The dimensions and skills of human resources in health positively affect the population's health status, particularly maternal-infant mortality rates. Building and strengthening the skills of health workers, offering continuous training, obtaining information about these workers' types and levels of skills, are means to develop the nursing workforce and are identified as issues from the "current crisis of human resources in health".

On the other hand, approaching scientific evidences to practice is another challenging aspect. In an editorial to The Lancet, published in 2012, it is informed that it is worrying that, despite the advances obtained in recent years, contemporary nursing continues not being based on scientific evidence ${ }^{(3)}$.

Undergraduate teaching plays a central role and is one of the ways to make students acquainted with scientific knowledge. Nursing curricula should include evidence-based practice, stimulate scientific reading, provide orientations on different ways to get access to scientific information and its role in safe and competent patient care. Thus, students gain skills to interpret, apply and assess evidence and will definitely be professionals who value continuous recycling and access to knowledge and scientific information. Finally, as ICN proposes, challenges exist to achieve the Millennium Development Goals by 2015 , the deadline, but reaching them may be possible, through global partnerships to develop and assess the obtained success.

These 60 years of EERP's dedication to nursing education and 20 years of RLAE's publication of the best scientific evidence to nursing and health disciplines in Latin American countries in particular, are examples of such successful partnerships.

In this special issue to commemorate RLAE's 20 uninterrupted years of circulation, readers have the opportunity to take over scientific knowledge that is applicable to practice, resulting from research by renowned experts in the area. 


\section{References}

1. Marziale MHP, Mendes, IAC. Pobreza e Desenvolvimento Humano: Estratégias Globais. Rev Latino-am Enfermagem 2007 setembro-outubro; 15(número especial):709-12.

2. World Health Organization. The world health report 2006 - working together for health [Internet]. Cited 2013 Feb 15. Available from: http://www.who.int/whr/2006

3. The Lancet. Science for action-based nursing. Lancet 2012;379:1763.

Silvia Helena de Bortoli Cassiani is Full Professor and Dean at Escola de Enfermagem de Ribeirão Preto, Universidade de São Paulo, WHO Collaborating Centre for Nursing Research Development, Brazil. E-mail shbcassi@eerp.usp.br. 